\title{
Economic and Operational Feasibility Analysis of Solid Waste Minimization Projects
}

\author{
Matthew J. Franchetti \\ The University of Toledo \\ USA
}

\section{Introduction}

The purposes of this chapter are to demonstrate a structured process to evaluate and determine the operational and economic feasibly of solid waste minimization projects that are based on proven financial engineering concepts. Many organizations are concerned with reducing solid waste levels, but few have the tools and necessary resources to evaluate and select among competing projects. These projects can range from fixed equipment purchases, such as balers or digesters, to implementing an office recycling program. This chapter provides a standardized business-based process to evaluate and select among competing solid waste minimization projects to determine which will best meet the organization's goals and maintain compatibility with existing processes. The analysis process involves identifying the benefits, costs, and drawbacks associated with each alternative project. To accomplish this, each alternative is evaluated based on: the impact on the program goal, technical feasibility, operational feasibility, economic feasibility, sustainability, and organizational culture feasibility. As a companion, a case study from Lucas County, Ohio (USA) is provided that demonstrates the analysis process. In addition, the paper explores the impact of uncertainty in decision making by highlighting economic efficiencies, sensitivity analysis, and changes to the data inputs, specifically inflation, recycling levels, and recycling commodity market shifts. This chapter may serve as an example or model for organizations considering the implementation of competing solid waste minimization projects.

\section{Screening alternatives}

The process of identifying waste minimization alternatives can generate numerous options. It would be very time consuming for the team to conduct a detailed financial and operational feasibility evaluation for each option. A quick screening process can help to rapidly identify the options worthy of full evaluation and the possible inclusion in the waste minimization program. Additionally, non-effective options can be removed, saving the team valuable time and money in the evaluation process. An effective screening process should be based on the original goals of the project and at a minimum should examine:

- The expected solid waste reduction (tons per year)

- The expected start up costs

- The impact to waste removal costs (\$ per year) 
- The impact to purchasing costs (\$ per year)

- The impact on employee moral

- The ease of implementation

The team should keep in mind that the goal of the screening the process is to quickly identify options worthy of further analysis. A weighted scoring system should be developed and applied to rank each alternative in an objective manner. A Quality Deployment Function, such as the 'House of Quality' is an excellent tool to accomplish this evaluation. A House of Quality is a graphic tool for defining the relationship between the organization needs and the capabilities. It utilizes a planning matrix to relate the organizational wants (for example solid waste reduction and cost performance) to how the waste minimization program will or can meet those wants (for example process changes or recycling efforts). It looks like a house with a correlation matrix as its roof and the organizational wants versus waste minimization options as the house structure. Another benefit of the House of Quality is that is may increase cross functional integration within the organizations using it, especially between marketing, engineering, and manufacturing.

Before proceeding with the screening process, the team should decide on the evaluation criteria (the "What's") and weighting system. A scale of $1-10$ for weighting each criterion is recommended. These weightings should be determined by the team, project manager, facility manager or a combination. The evaluation criteria should be directly related to the overall goals of the project, such as:

- Reduction in waste amounts

- Reduction in waste toxicity

- Reduction to waste disposal costs

- Reduction in purchasing costs

- Revenue generation potential

- Low start up costs

- Productivity improvements

- Quality improvement

- Ease of implementation

- Impact on employee morale

- Impact on organization image

- Impact on safety

- Other factors as determined by the team

Once these criteria have been created, the team should rank them on a scale of 1 to 10 based on importance. For example, regulatory compliance of each option may receive an importance rating of 10 (meaning that it is highly important). On the other hand, a criterion such as low start up costs may receive an importance rating of 2 (meaning that start-up costs are of low importance and not a major concern in the decision-making process).

Once the criteria and importance ratings have been established, the team should list each alternative in the rows of a spreadsheet. In the row for each alternative, the team should place a rating score corresponding to the level of which the alternative meets the criterion with 0 being no or very low impact and 10 representing great impact. For example, if the team is considering the purchase of a cardboard baler, the reduction in waste amounts could be significant, so the team may rate it a an 8 , but in the start up cost criterion, the team may rate it lower, such as a 1, due to the high implementation cost to purchase the baler. Once each alternative is rated, the ratings should be multiplied by the importance factor and each 
row should be summed. This score will allow the team to objectively screen each alternative. Once all of the alternatives are listed and scored, the team can screen them based on there total score. Alternatives with higher total scores pass the screening process and become eligible for further evaluation. To determine the cut-off point, several methods may be applied that depend on time and money resources. For example, the team may set the minimum threshold at a specific point value, accept the top $20 \%$, or accept the top ten for further analysis. When first starting a solid waste minimization program it is recommended that the team select the top third (33\%) of all alternatives for further screening to compensate for estimation errors.

\section{Analyzing and selecting alternatives}

After reducing the list of alternatives using the screening process discussed in Section 1, the remaining alternatives should be further analyzed to determine the best fit for the organization to minimize solid waste and hence include in the program. The analysis process will identify the benefits, costs, and drawbacks of each alternative. To accomplish this, each alternative is evaluated based on:

- The impact on the program goal

- Technical feasibility

- Operational feasibility

- Economic feasibility

- Sustainability

- Organizational culture feasibility

The key outcome of this phase is to fully document, analyze, and arrive at a final acceptance decision for each alternative. To accomplish this outcome, the process flow charts are analyzed; the annualized amount of solid waste generated is determined; a complete feasibility analysis is completed (including technical, operational, organization), a cost justification study is conducted; feedback is collected and analyzed; and finally a decision is made regarding each alternative (to implement or not implement). These studies provide a complete discussion and documentation for each alternative that will be used in the implementation phase if the alternative is accepted for implementation. During this process, the team must keep a clear understanding of the overriding goals of the waste minimization project. For example, the relative importance of reducing costs versus minimizing environmental impact. Some alternatives may require extensive analysis, including the need to gather additional data from vendors or to analyze market trends for recyclable material commodity markets. The first consideration when evaluating alternatives is its impact on the goals of the project established in the first phase of the project. These goals can range from in solid waste generation to the cost benefits associated with waste minimization. Efforts should first be made to reduce waste generation, next to reuse waste materials, next recycling (in and out of process) and finally disposal in a landfill. The idea behind the hierarchy is to engineer methods to eliminate the generation of a waste stream altogether and hence eliminate the need to manage the solid waste stream via recycling or landfill disposal. Alternatives should be separated into different categories to aid with this process. The categories are (based on the solid waste management hierarchy):

- Waste prevention alternatives

- Reuse alternatives

- $\quad$ Recycling alternatives 
- Composting alternatives

The evaluation process itself, consists of seven steps to study each alternative. The process is completed sequentially and after each step, the alterative is accepted and 'moves' to the next phase or is rejected and the analysis is terminated without further steps being completed. If the alternative does not meet thresholds or feasibility tests, it is eliminated from further review to save the team time and resources. The alternative should still be kept on file in the event that technology or organizational changes render the option feasible. The seven steps are listed below:

1. Fully describe each alternative in terms of the equipment, raw material, process, or purchasing additions or modifications

2. Calculate the annualized waste reduction impact in terms of tons per year and whether the alternative is related to source reduction, reuse, or recycling

3. Compile and analyze the process flow charts that created the waste stream

4. Conduct a feasibility analyses (technical, operational, and organizational)

5. Conduct a cost justification for each alternative (payback, internal rate of return, and net present value)

6. Gather feedback from all stakeholders (internal and external)

7. Gain approval and sign off from the waste minimization team and organizational executives

\subsection{Technical and operational feasibility}

Technical and operational feasibility are concerned with whether the proper resources exist or are reasonably attainable to implement a specific alternative. This includes the square footage of the building, existing and available utilities, existing processing and material handling equipment, quality requirements, and skill level of employees. During this process, product specifications and facility constraints should be taken into account. A typical technical evaluation criterion includes:

- Available space in the facility

- Safety

- Compatibility with current work processes and material handling

- Impact on product quality

- Required technologies and utilities (power, compressed air, data links)

- Knowledge and skills required to operating and maintain the alternative

- Addition labour requirements

- Impact on product marketing

- Implementation time

When evaluating technical feasibility, the facility engineers or consultants should be contacted for input. In addition, it is also wise to discuss the technical aspects with the workers directly impacted by the change such as production and maintenance. If an alternative calls for a change in raw materials, the effect on the quality the final project must be evaluated. If an alternative does not meet the technical requirements of the organization, it should be removed from consideration. From a technical standpoint, the three areas that require additional evaluation are:

- Equipment modifications or purchases

- Process changes

- Material changes 
If an alternative involves an equipment modification or purchase, an analysis for the equipment should be conducted. The team should investigate whether the equipment is available commercially and gather contact information/data from the manufacturer. Performance of the machine should also be addressed, including cost, utility requirements, capacity, throughput, cycle time, required preventative maintenance, space requirements, and possible locations in the facility that the equipment could be installed. In addition, if production would be affected during installation, this should be evaluated as well. The vendor or manufacturer may provide additional information regarding potential shut downs or delays. Required modifications to workflow or production procedures should be analyzed and any required training or safety concerns related to the equipment purchase should be reviewed. From an operational standpoint, attention should be given to how the alternative will improve or reduce productivity and labour force reductions or increases.

If a waste minimization alternative involves a process change or a material change, the impacted areas should be identified and feedback should be gathered from the area managers, employees, maintenance, and engineers (if applicable). With process changes, training requirements should also be discussed and determined. Also, the impacts on production, material handling/storage, and quality should be addressed. A material testing program is highly recommended for new items that the engineering team may not be familiar with so that they can analyze the impacts to quality and throughput. A design of experiment (DOE) that tests the changes versus the current material is an excellent method to gauge impacts. A DOE is the design of data gathering tests in which variation is present. Often the experimenter is interested in the effect of some process or intervention, such as using a new raw material, on some outcome such as quality.

\subsection{Economic feasibility}

From an economic standpoint, traditional financial evaluation is the most effective method to analyze alternatives. These measures include the payback period, (discounted payback period), internal rate of return, and net present value for each alternative. If the organization has a standard financial evaluation process, this should be completed for each alternative. The accounting or finance department or the organization should have this information. To perform these financial analyses, revenue and cost data must be gathered and should be based on the expectations for the alternatives. This may be complicated, especially if a project will have an impact on the number the required labour hours, utility costs, and productivity, or require initial investments or start-up funds. A comprehensive estimation of the cost impacts (revenues and costs) per year over the life of the alternative is required to begin the analysis. The first step of the economic evaluation process is to determine these costs. These costs include capital costs (or initial investment), operating costs/savings, operating revenue, and salvage values for each waste minimization alternative.

Capital costs are the costs incurred when purchasing assets that are used in production and service. Normally they are non-reoccurring and used to purchase large equipment such as a baler or plastic grinder. Capital costs include more than just the actual cost of the equipment; they also include the costs to prepare the site for production. Following is a brief list of typical capital costs; also know as the initial investment:

- $\quad$ Site development and preparation (including demolition and clearing if needed)

- Equipment purchases including spare parts, taxes, freight, and insurance

- Material costs (piping, electrical, telecommunications, structural) 
- $\quad$ Building modification costs (utility lines, construction costs)

- Permitting costs, building inspection costs

- Contractor's fees

- Start up costs (vendor, contractor, in-house)

- Training costs

After the initial investment has been calculated, the reoccurring costs, savings, and revenues from the waste minimization alternative must be determined. The concept is to reduce waste disposal and raw material costs based on the implementation of the alternative that is being analyzed. For example, if a company considers the installation of a cardboard baler, the annual operating costs of the baler (such as labour and utilities), the annual cost savings from reduced disposal costs, and the revenue from the sale of the baled cardboard must be considered. Reducing or avoiding present and future operating costs associated with solid waste storage and removal are critical elements of the solid waste minimization process. Due to increased solid waste disposal costs (in the range of $\$ 30$ - $\$ 80$ per ton in the US); many companies are finding that the cost of waste management has become a significant factor in their cost structures. Some common reoccurring costs include:

- Reduced solid waste disposal costs - waste generation is reduced or is diverted to recycling streams resulting is less waste is being sent to the landfill for disposal and lower hauler charges. These include disposal fees, transportation costs, and predisposal treatment costs.

- Input material cost savings - options that reduce scrap, reduce waste or increase internal recycling tend to decrease the demand for input materials

- Changes in utility costs - utility costs may increase or decrease depending on the installation, modification, or removal of equipment

- Changes in operating and maintenance labour/benefits - an alternative may increase or decrease labour requirements and the associated benefits. The may be reflected in changes in overtime hours or in the number of employees.

- Changes in operating and maintenance supplies - an alternative may result in increased or decreased operating and maintenance supply usage.

- Changes in overhead costs - large projects may increase or decrease these values.

- Changes in revenues for increased (or decreased production) - an alternative may result in an increase in the productivity of a unit. This will result in changes in revenue.

- Increase revenue from by-products - an alternative may generate a by-product that can be sold to a recycler or sold to another company as material. This will increase a company's revenue.

It is suggested that savings in these costs be taken into consideration first, because they have a greater impact on the project's cash flows and involve less effort to estimate reliably. The remaining elements usually have a smaller impact and should be included on an as-needed basis or to fine-tune the analysis.

A project's profitability is measured by estimating the net cash flows each operating year over the life of the project. A net cash flow is calculated by subtracting the cash outlays from the cash incomes starting at the beginning of the project (the year the project is initiated).

If a project does not have an initial investment, the project's profitability can be evaluated by whether an operating cost savings occurred or not. If such a project reduces overall operating costs, it should be implemented. For example, suppose an organization currently recycles plastics and metals. If the organization currently ships comingled plastics and 
metals to a recycling processor, a process change could be implemented that requires employees to separate plastics from metals before shipment. There is little to no initial investment for this example, but there will be added labour costs for separation versus the additional revenue generated by the finer sort to the processor. If the additional revenues outweigh the additional costs, the alternative should be implemented.

For projects with significant initial investments or capital costs, a more detailed profitability analysis is needed. The three standard measures of profitability are:

- Payback period

- Internal rate of return (IRR)

- $\quad$ Net present value (NPV)

The payback period for a project is the amount of time required to recover the initial cash outlay for the project. The formula for calculating the payback period is on a pre-tax basis in years is:

$$
\text { Payback Period }=\frac{\text { Capital Investment }}{\text { Annual operating cost savings }}
$$

For example, suppose a manufacturer installs a cardboard baler for a total cost of $\$ 65,000$. If the baler is expected to save the company $\$ 20,000$ per year, then the payback period is 3.25 years. Payback period is typically measured in years; however, some alternatives may have payback periods in terms of months. Many organizations use the payback period as a screening method before conducting a full financial analysis. If the alternative does not meet a predetermined threshold, the alternative is rejected. Payback periods in the range of three to four years are usually considered acceptable for low risk investments. Again, this method is recommended for quick assessments of profitability. If large capital expenditures are involved, it should be followed by a more strenuous financial analysis such at the IRR and NPV.

The internal rate of return (IRR) and net present value (NPV) are both discounted cash flow techniques for determining profitability and determining if a waste minimization alternative will improve the financial position of the company. Many organizations use these methods for ranking capital projects that are competing for funds, such as the case with the various waste minimization alternatives. Capital funding for a project can depend on the ability of the project to generate positive cash flows beyond the payback period to realize an acceptable return on investment. Both the IRR and NPV recognize the time value of money by discounting the projected future net cash flows to the present. For investments with a low level of risk, an after tax IRR of 12 to $15 \%$ if typically acceptable.

The formula for NPV is:

$$
N P V=\sum_{t=0}^{N} \frac{C_{t}}{(1+r)^{t}}
$$

Each cash inflow/outflow is discounted back to its present value (PV). Then they are summed. Therefore

Where

- $\quad \mathrm{t}$ - the time of the cash flow 
- $\quad \mathrm{N}$ - the total time of the project

- $\quad \mathrm{r}$ - the discount rate (the rate of return that could be earned on an investment in the financial markets with similar risk.)

- $\quad \mathrm{C}_{\mathrm{t}}$ - the net cash flow (the amount of cash) at time $\mathrm{t}$ (for educational purposes, $\mathrm{C}_{0}$ is commonly placed to the left of the sum to emphasize its role as the initial investment).

The internal rate of return (IRR) is a capital budgeting metric used by firms to decide whether they should make investments. It is an indicator of the efficiency of an investment, as opposed to net present value (NPV), which indicates value or magnitude. The IRR is the annualized effective compounded return rate which can be earned on the invested capital, i.e., the yield on the investment.

A project is a good investment proposition if its IRR is greater than the rate of return that could be earned by alternate investments (investing in other projects, buying bonds, or investing the money in a bank account). Thus, the IRR should be compared to any alternative costs of capital and should include an appropriate risk premium.

Mathematically, the IRR is defined as any discount rate that results in a net present value of zero for a series of cash flows. In general, if the IRR is greater than the project's cost of capital, or hurdle rate, the project will add value for the company. The equation for IRR is:

$$
N P V=\sum_{t=0}^{N} \frac{C_{t}}{(1+r)^{t}}=0
$$

Most spreadsheet programs typically have the ability to automatically calculate IRR and NPV form a series of cash flows. Following is an example applying these financial evaluation concepts. For example, the baler case study discussed previously had an initial cost of $\$ 65,000$ and $\$ 20,000$ in annual savings. Additionally, the assumed baler life span was 10 years and an organization minimum attractive rate of return (MARR) was $15 \%$. The MARR is the is the minimum return on a project that a manager is willing to accept before starting a project, given its risk and the opportunity cost of foregoing other projects. The following cash flows, IRR, and NPV result:

\begin{tabular}{|l|l|}
\hline Year & Cash Flow \\
\hline 0 & $\$(65,000)$ \\
\hline 1 & $\$ 20,000$ \\
\hline 2 & $\$ 20,000$ \\
\hline 3 & $\$ 20,000$ \\
\hline 4 & $\$ 20,000$ \\
\hline 5 & $\$ 20,000$ \\
\hline 6 & $\$ 20,000$ \\
\hline 7 & $\$ 20,000$ \\
\hline 8 & $\$ 20,000$ \\
\hline 9 & $\$ 20,000$ \\
\hline 10 & $\$ 20,000$ \\
\hline IRR & $28.2 \%$ \\
\hline NPV & $\$ 30,761$ \\
\hline
\end{tabular}

Table 1. Net present value analysis 
As shown in the last two rows of Table 1, the IRR is $28.2 \%$ and the NPV is nearly $\$ 31,000$ at a MARR of $15 \%$. The fact that the IRR is greater than the 15\% MARR and the fact that the NPV is positive indicates that the project is a good financial decision.

\subsection{Sustainability and organisational culture feasibility}

Waste minimization alternatives should also be evaluated based on sustainability and the cultural fit within the organization. Sustainability is defined as an organization's investment in a system of life, projected to be viable on an ongoing basis that provides quality of life for all individuals and preserves natural ecosystems. Sustainability in its simplest form describes a characteristic of a process that can be maintained at a certain level indefinitely. The term, in its environmental usage, refers to the potential longevity of vital human ecological support systems, such as the planet's climatic system, systems of agriculture, industry, forestry, fisheries, and the systems on which they depend. In other words, the waste minimization alternatives should be evaluated based on how well they meet this definition, such that the alternative can be sustained without large amounts of effort or additional resources and continue to protect the environment. Often, this will be related to the culture of the organization. Criteria commonly used to evaluate the sustainability of an alternative include:

- Dealing transparently and systemically with risk, uncertainty and irreversibility

- Ensuring appropriate valuation, appreciation and restoration of nature

- Integration of environmental, social, human and economic goals in policies and activities

- Equal opportunity and community participation/Sustainable community

- Conservation of biodiversity and ecological integrity

- Ensuring inter-generational equity

- Recognizing the global integration of localities

- A commitment to best practice

- No net loss of human capital or natural capital

- The principle of continuous improvement

- The need for good governance

When an alternative involves working with a recycler or commodity broker there are several key questions to ask potential candidates to determine the best fit for the organization. Those questions include:

- What types of materials does the company accept and how must they be prepared?

- What contract terms does the buyer require?

- Who provides the transportation?

- What is the schedule of collections?

- What are the maximum allowable contaminant levels and what is the procedure for dealing with rejected loads?

- $\quad$ Are there minimum quantity requirements?

- Where will be recyclable material be weighed?

- Who will provide containers for recyclables?

- Can "escape clauses" be included in the contract?

- Be sure to check references.

In a similar way, when working with equipment vendors, there a several key questions to consider: 
- What is the total cost of the equipment including freight and installation?

- What are the building requirements and specifications for the equipment (compressed air, electricity, space, minimum door widths)?

- Does a service contract included in the purchase price or is there an additional charge?

- Do you offer training to the employees, engineers, and maintenance employees that will be working with the equipment, if so, is there a charge?

- What is the process if the equipment malfunctions and the company needs support, is there a representative available 24 hours per day? What is the charge for these visits?

- Do you offer an acceptance test process to ensure that the equipment operates within the promised specifications (capacity and cycle time)?

- What is the required installation time and must production be shut down?

\section{Case study}

In 2008, the Lucas County Solid Waste Management District (District) located in Ohio, USA, considered the purchase of a material recovery facility (MRF) to sort and sell nearly 10,000 tons recyclable materials that were collected per year from its municipal recycling programs. This section analyzes the economic and operational feasibility of the MRF as an option for processing recyclable materials and may serve as an example for other local governments considering the implementation of such a system. A strong emphasis is placed on economic efficiencies and a sensitivity analysis is also discussed. A break-even analysis is discussed to determine the degree by which the existing conditions would need to change in order to allow such a facility to become feasible (or infeasible).

Based on a literature review of previous research conducted in this field, three relevant articles were found. The first was published in 1995 and is titled "The development of material recovery facilities in the United States: status and cost structure analysis" (Chang and Wang, 1995). This article examined a fast track MRF development in the U.S. and the related operating and cost structures. The purpose of the paper was to create solid waste management strategies and to aid in future investment forecasting or policy decisions. The second paper was published in 2005 and is titled "Sustainable pattern analysis of a publicly owned material recovery facility in a fast-growing urban setting under uncertainty" (Daliva and Chang, 2005). This research applied grey integer programming techniques to screen optimal shipping patterns and the outcome was an ideal MRF location and capacity design. The final paper was a report published in 1994 by the Pennsylvania Department of Environmental Protection and is titled "Lycoming County Material Recovery Facility Evaluation" (Beck, 2004). This research evaluated the operational efficiency and cost/revenue of a Lycoming County MRF. The paper also identified methods that the facility, and others like it, could be made more financially sustainable over the long term.

\subsection{Methodology}

The methodology used to conduct this research was based on the principles outlined in the third edition of "Facilities Planning" (Tompkins, et. al., 2003). This book provides an industrial engineering basis for defining facility requirements, identifying equipment needs, developing layouts, and implementing facility plans. This research examined the hypothesis that a county owned MRF could be cost justified and financially advantageous versus the 
current system of outsourcing in Lucas County, Ohio. The assumptions for this case study included:

- $\quad$ The useful life of the MRF is 20 years (2007 to 2027)

- A minimum attractive rate of return (MARR) of 15\% was fixed over the 20 year project life for financial decisions

- Recycling levels would increase at annual rates of $5 \%$ for fiber, $3 \%$ for plastics, $2 \%$ for glass, and remain constant for metals over the 20 year project life.

- Recycling commodity prices would remain increase at a rate of $2.5 \%$ the 20 year project life.

- Utility costs would increase at a rate of $2.5 \%$ per year over the 20 year project life (inflation).

- Labour and benefit costs would increase at a rate of $3.5 \%$ per year over the 20 year project life (inflation).

The first phase of the analysis process involved estimating the current recycling levels in terms of materials compositions and volumes (annual tonnages). These data were collected from District records from the 2007 fiscal year and included operating cost and revenue data. Once combined, this information provided a complete baseline of the operations of the current system utilizing the outsourced processes. This baseline was used to compare the cost structure of acquiring a county owned and operated MRF. The baseline data provided annualized costs and revenues associated with the existing drop-off recycling program, specifically:

- Revenue paid from third party processors for recyclable materials

- Third party processing fees

- Labour costs

- Administrative costs

- Vehicle costs (fuel, maintenance, repair)

- Drop off container and material costs

The second phase involved indentifying potential MRF sites. A local business realtor was contacted for assistance. Upon the identification of the optimal MRF site, a complete annual cost and revenue projection was conducted to operate the MRF over a 20 year period. This analysis included the following annualized costs and revenues:

- Revenue paid from third party recycling material commodity brokers

- $\quad$ Building purchase cost (including realtor fees)

- Building modification and renovation costs

- Equipment and inspection/repair costs

- Labour costs (including driver and processors)

- Administrative costs

- Utility costs

- Vehicle costs (fuel, maintenance, repair)

- $\quad$ Drop off container and material costs

This financial projection of the proposed MRF was compared with the current system baseline. In essence, the analysis answered the question whether the additional revenue earned from the sale of the processed recyclable materials outweighed the additional capital and operating costs over the projected 20 year life of the project at a $15 \%$ minimum attractive rate of return. To accomplish this analysis, a net present worth (NPW) was conducted. This method not only allows the selection of a single project based on the NPW 
value and in the case of this case study, the existing system of outsourcing versus purchasing and operating a county owned MRF.

To find the NPW of a project an interest rate is needed to discount the future cash flows. The most appropriate value to use for this interest rate is the rate of return that one can obtain from investing the money elsewhere. Alternatively, it may be the rate that an organization will be charged if it had to borrow the money. The selection of this rate is a policy decision by organizational management and is usually based on market conditions.

To begin this process, the District determined the net cash flow in each period over the service life of the project. Considering the MARR, each of these net cash flows was discounted back to the present time (year zero at the start of the project). The magnitude of NPW determines whether the project is accepted or rejected. If NPW is positive, the decision is to accept the project. If it is negative, then the investment is not worthwhile economically. If it is zero, then the project does not make a difference economically.

It is also possible to conduct a break-even interest rate analysis by varying the value of the interest rate while computing the NPW of a project. The break-even interest rate is the rate at which NPW is zero. The break-even interest rate is also known as the internal rate of return (IRR).

\subsection{Overview of the current recycling process}

Recycling services provided by the District to the local community are accomplished via a drop-off program. In Lucas County, the District collects two recycling streams from over 60 drop off sites throughout the community. These two material streams are commingled paper products and commingled containers. The drop-off sites are located at grocery stores, schools, metro parks, township offices, and large apartment complexes. Each drop off site has at least two five-cubic yard dumpsters, one for each recycling stream. At high volume sites, multiple containers are utilized for the two recycling streams. Below is a summary of the total tons of each waste collected in 2006 at the drop-off sites:

- $\quad 4,368$ tons of ONP and MOP

- $\quad 2,912$ tons of OCC

- 1,493 tons of glass bottles

- 677 tons of plastic bottles

- 235 tons of steel cans

- 70 tons of aluminium cans

\subsection{Current system costs and revenue}

Under the current system the District's drop-off program was operating at a $\$ 425,462$ loss per year considering revenue minus expenses. The loss is offset by additional revenue generated by the District. The additional revenue is primarily generated from a $\$ 3$ per ton surcharge on all solid waste generated in Lucas County. This surcharge is collected by the landfills that serve Lucas County and amounts to approximately $\$ 1.5$ million per year.

Under the current contract the District has entered with a third party processor, the District generates the following revenue per ton of material (please note the District is paid based on commingled materials that require additional sorts):

- $\quad \$ 37.08$ per ton of commingled fiber (OCC, MOP, ONP)

- \$23.35 per ton of commingled containers (aluminium/steel can and plastic) 
Per year, the District generates $\$ 327,734$ from the sale of recyclables to the third party processor. This revenue is offset by the following annual costs:

- $\$ 350,196$ for truck diesel fuel costs

- $\$ 5,500$ for annual maintenance costs

- $\$ 7,500$ for drop-off site container costs and maintenance

- \$240,000 for trucdk driver salaries and benefits for the four drivers employed by the District (one drive is a team leader that operates a vehicle as needed)

- $\$ 150,000$ for administrative costs which include the Solid Waste District Manager's and administrative assistant's salary and benefits in addition to supply costs.

\subsection{Proposed system costs and revenue}

Under the proposed system the District's drop-off program will operate at an $\$ 189,327$ loss per year considering revenue minus expenses. The revenue generated from the sale of the sorted recyclable materials was calculated using the current values of the Chicago material prices listed below (current as of 2/2008):

- $\quad$ Mixed office paper - $\$ 82 /$ baled ton

- White ledger - $\$ 102 /$ baled ton

- Newspaper - $\$ 55 /$ baled ton

- Cardboard - $\$ 110 /$ baled ton

- Aluminum cans - $\$ 180 /$ crushed and baled ton

- Steel cans - $\$ 180 /$ crushed and baled ton

- Plastic bottles - $\$ 180 /$ crushed and baled ton

- Glass bottles - $\$ 25 /$ ton

Based on the forecasted volumes and commodity prices, the District will generate $\$ 844,197$ annually from the sale of the recyclable materials to commodity brokers. From an expense standpoint, the new system will require additional money to operate and to maintain the MRF, specifically, the cost of the building, labour costs, utility, costs, maintenance costs, and management/administrative costs. The cost of the building will be addressed in the comparison and justification portion of this chapter. Specifically, the costs for the proposed system are:

- $\$ 365,100$ for truck diesel fuel costs (this is up slightly from the current system due to the location of the proposed MRF and the additional required miles for the trucks to deposit material there)

- $\$ 5,500$ for annual maintenance costs (no change from the current system)

- $\$ 7,500$ for drop-off site container costs and maintenance (no change from the current system)

- $\$ 240,000$ for truck driver salaries and benefits for the four drivers employed by the District (no change from the current system)

- $\$ 186,400$ in labour costs for employees to operate the MRF (these were discussed in the previous section)

- $\$ 190,000$ for administrative costs which include the Solid Waste District Manager's and administrative assistant's salary and benefits in addition to supply costs (the proposed system includes $\$ 40,000$ for a District employee to supervise the MRF)

- $\$ 39,024$ in utility and building maintenance costs for the MRF

The utility and building maintenance costs were estimated from the current costs of the proposed site as determined from existing records. 


\subsection{Financial comparison and analysis}

To complete the financial analysis the Full Cost Accounting for Municipal Solid Waste, published the US Environmental Protection Agency, was used as a guide (US EPA, 2006). The proposed system will result in an annual cost savings of \$236,135 versus the existing system of outsourcing. This was calculated by taking the projected annual net revenue (cost) of the proposed system minus the annual net revenue (cost) of the current system. Both system will result in a net cost for the District, $(-\$ 189,327$ for the proposed system minus $\$ 425,462$ of the current system). The initial investment for the proposed system, which includes the cost of the building and renovations, is $\$ 973,050$. The breakdown for this amount is $\$ 900,000$ for the building and equipment and an additional $\$ 73,050$ to refurbish the building and equipment. The $\$ 73,050$ is the total amount provided by contactors based on inspection of the building and equipment. The payback period for the proposed system is 4.12 years (or four years and 1.5 months) and the internal rate of return for the first five years of operation is $6.8 \%$ and $20.5 \%$ for the first 10 years of operation. Working with the Lucas County Commissioners a $\$ 1,000,000$ bond at $6 \%$ interest will be established with a 20 year payback period to acquire the fund for the initial investment of $\$ 973,050$.

\subsection{Breakeven and sensitivity analysis}

From a financially standpoint, the proposed system has a payback period 4.12 years and an internal rate of return of $20.5 \%$ over 10 years based on the market assumptions stated earlier. A critical concern involves analyzing changes to these assumptions and the impact to the decision to implement. The breakeven point and a sensitivity analysis of the proposed system based on changes in market conditions will answer address this concern. From a breakeven standpoint, two market changes were analyzed:

- The lowest level that the amounts of material recycled (in tons) by the District could fall and still achieve a 10 year IRR of $6.5 \%$

- The lowest level that the dollar values of the waste commodities could fall and still achieve a 10 year IRR of $6.5 \%$

The breakeven point for the amount of materials collected by the District and the dollar values for the waste commodities was analyzed. An analysis of the data indicated that the amount of materials collected by the District could drop by $13 \%$ or 1,300 tons from the estimate to achieve an IRR of $6.5 \%$. This would amount to an $\$ 110,000$ reduction in revenue per year for the District. On average, the amount of materials collected by the District has increase by $3 \%$ to $5 \%$, so this is not a large concern. Similarly, the dollar values provided by the commodity brokers based on the market rates could drop and average of $13 \%$ for each material type from the current conditions to achieve an IRR of $6.5 \%$. This would also amount to an $\$ 110,000$ reduction in revenue per year for the District.

A sensitivity analysis was conducted to determine which variables would have the largest impact on the revenue target, hence meeting the IRR, if they were reduced. To accomplish this, each variable was reduced by $5 \%$ while all other variables were held constant and the percent change in revenue was measured. The variables analyzed were:

- Amounts of materials collected (measured in tons)

- Dollar value per ton of recycling material

From this analysis OCC amounts and their price were most sensitive to changes and therefore have the largest impact on total revenue and IRR. A 5\% reduction in the amount collected annually or the dollar value per ton of OCC reduced the total revenue by $2 \%$. 
Likewise, a 5\% reduction in ONP reduced total revenue and IRR by $1 \%$. All other variables did not indicate a high level of sensitivity.

\subsection{Conclusions}

This case study demonstrated the process for municipalities to economically justify the purchase and operation of a government owned MRF. Key findings from this research revolve around a case study from the 2008 purchase of a government owned MRF in Ohio, USA. The key findings were demonstrated through a complete financial analysis. Specifically, the financial analysis indicated that the municipality would achieve a payback period of approximately four years, and a ten year internal rate of return of $20.5 \%$. The consequences of these findings, stemming from the economic and operational justification, led to the actual purchase of the MRF site and subsequent operation in 2008 through early 2011. This research may serve as an example or model for other local governments considering the implementation of such a system.

A strong emphasis was placed on economic efficiencies and a sensitivity analysis of the results to changes in the data inputs, specifically inflation, recycling levels, and recycling commodity market shifts. A break even analysis of the data indicates that the amount of materials collected by the District or the commodity prices could drop by $13 \%(\$ 110,000)$ from the estimate to achieve an IRR of $6.5 \%$. On average, the amount of materials collected by the District has increased by $3 \%$ to $5 \%$, so this is not a large concern. The sensitivity analysis indicated that OCC amounts and price are most sensitive to changes and therefore have the largest impact on total revenue and IRR. A 5\% reduction in the amount collected annually or the dollar value per ton of OCC reduces total revenue by $2 \%$. All other variables did not indicate level a high level of sensitivity.

Reservations of limitations of this research include:

- Location and the cost of business in various geographical areas

- Inflation

- Recycling commodity market shifts

- Competition

This research and MRF analysis was conducted in the Midwest, which has a relatively lower business and real estate costs versus the East or West Cost. Conducting a similar study in these areas may not be economically justified based on these higher costs. Major changes in inflation (labour and operating costs) or commodity market shifts may alter the economics of the ten year cost structure. Finally, unforeseen competition arising in the area could reduce material collection amounts, hence reducing revenues. This competition could present itself as a new private sector recycling collector/processor or as modified fee structures from existing companies. The likelihood of these events over the ten year time frame is relatively low due to these companies current cost structures and taxation rates.

\section{References}

Beck, R.W. (2004). Lycoming County Material Recovery Facility Evaluation. Pennsylvania Department of Environmental Protection. Final Report.

Chang, N. and Wang, S.F. (1995). The development of material recovery facilities in the United States: status and cost structure analysis. Resources, Conservation and Recycling. 13: 115 - 128; 
Davila, E. and Chang. N. (2005). Sustainable pattern analysis of a publicly owned material recovery facility in a fast-growing urban setting under uncertainty. Journal of Environmental Management. 75: 337 - 351;

Tompkins, White, Bozer, and Tanchoco. (2003). Facilities Planning. John Wiley and Sons, Inc., Hoboken, NJ, USA.

US Environnemental Protection Agency. (2006). Full Cost Accounting for Municipal Solid Waste Management. 


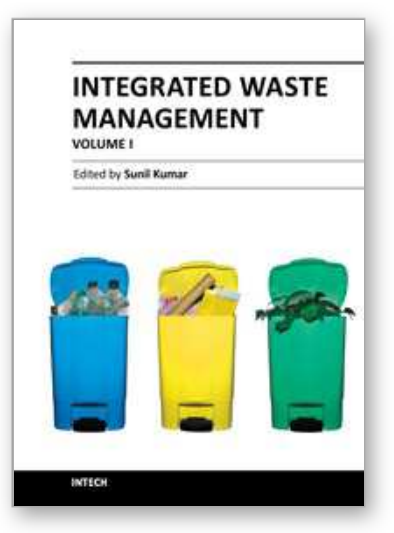

\author{
Integrated Waste Management - Volume I \\ Edited by Mr. Sunil Kumar
}

ISBN 978-953-307-469-6

Hard cover, 538 pages

Publisher InTech

Published online 23, August, 2011

Published in print edition August, 2011

This book reports research on policy and legal issues, anaerobic digestion of solid waste under processing aspects, industrial waste, application of GIS and LCA in waste management, and a couple of research papers relating to leachate and odour management.

\title{
How to reference
}

In order to correctly reference this scholarly work, feel free to copy and paste the following:

Matthew J. Franchetti (2011). Economic and Operational Feasibility Analysis of Solid Waste Minimization Projects, Integrated Waste Management - Volume I, Mr. Sunil Kumar (Ed.), ISBN: 978-953-307-469-6, InTech, Available from: http://www.intechopen.com/books/integrated-waste-management-volume-i/economic-andoperational-feasibility-analysis-of-solid-waste-minimization-projects

\section{INTECH}

open science | open minds

\section{InTech Europe}

University Campus STeP Ri

Slavka Krautzeka 83/A

51000 Rijeka, Croatia

Phone: +385 (51) 770447

Fax: +385 (51) 686166

www.intechopen.com

\section{InTech China}

Unit 405, Office Block, Hotel Equatorial Shanghai

No.65, Yan An Road (West), Shanghai, 200040, China

中国上海市延安西路65号上海国际贵都大饭店办公楼405单元

Phone: +86-21-62489820

Fax: +86-21-62489821 
(C) 2011 The Author(s). Licensee IntechOpen. This chapter is distributed under the terms of the Creative Commons Attribution-NonCommercialShareAlike-3.0 License, which permits use, distribution and reproduction for non-commercial purposes, provided the original is properly cited and derivative works building on this content are distributed under the same license. 